\title{
Museografía en el tiempo. Análisis de una exposición universitaria conmemorativa en 1979
}

\author{
Ilihutsy Monroy Casillas \\ Lizbeth Ramírez Chávez
}

\footnotetext{
-
} n las sociedades contemporáneas la asistencia a los museos es una actividad no sólo educativa o de prestigio cultural sino también recreativa, por lo que éstos han reformulado servicios e incorporado nuevas tecnologías con el objeto de atraer a diferentes públicos (Morales Moreno 1996:87). A raíz de estas transformaciones nos preguntamos por exposiciones y museos que nos antecedieron: ¿cómo eran, qué ideas transmitían, cómo se organizaban?

Este artículo tiene la finalidad de responder a estas dudas a partir de desentrañar el quehacer museográfico de la exposición 1929-1979. Autonomía Universitaria UNAM, ${ }^{1}$ producto de gran envergadura porque significó hacer un pertinente balance institucional no sólo de la autonomía universitaria sino, esencialmente, de la propia Universidad Nacional Autónoma de México (UNAM). Como objeto de estudio para la investigación histórica y museológica de las exposiciones universitarias, la muestra presenta muchas ventajas, ya que el testimonio de su contexto e intenciones se conserva en el Archivo Histórico de la UNAM (Monroy 2010), además de que existen otras fuentes documentales que nos permiten recrearlos.

Los estudios sobre museografía pocas veces se centran en este tema. Por ejemplo, La universidad en el umbral del siglo XXI (UNAM 1988:9) concentra su mirada en la planeación y el montaje, en el Palacio de Minería, de la exposición de 1987 así titulada: al referir los antecedentes museográficos, considera la exposición de 1979 — a la que, junto con otras más del periodo, Luisa Fernanda Rico Mansard (2003:87) define como "detonantes para la revaloración de las actividades museológicas y museográficas llevadas a cabo hasta entonces en la UNAM" - como un parteaguas, ya que abrió las puertas a los interesados en el estudio de las colecciones universitarias, al organizar más de 50 muestras de la propia universidad.

Por su interés sobre la historia de la museografía universitaria mexicana, destaca el texto de Rico Mansard (2003:68), en el que propuso una expli-

\footnotetext{
${ }^{1}$ Aunque retomamos el nombre de la exposición consignado en AHUNAM/COE s. f.a, es necesario aclarar que todo indica que no tuvo uno oficial, aunque se la conoció familiarmente como "la Exposición", y así nos referiremos a ella en la mayor parte de este artículo.
} 
cación de su desarrollo, dividida en las siguientes tres etapas: formación, "periodo dedicado a la reunión, investigación y exhibición de piezas"; transición, "época de revaloración, distribución y reubicación de las colecciones", y proyección, "periodo en que la museografía universitaria alcanza altos niveles de especialización, asumiendo papeles vanguardistas que traspasaron los ámbitos académico y nacional", idea de la que, por supuesto, partimos en este artículo. Esto va de acuerdo con lo enunciado por Soichiro Tsuruta (cfr. Lacouture Fornelli 1996:19), quien engloba esos tiempos en la "era de la museología y de la museografía", la cual se distingue por su investigación científica. No olvidemos que en el ámbito museográfico empezó en los años setenta una decidida discusión sobre la metodología, por lo que aparecieron las primeras publicaciones de los antecedentes de la que se conocería como Nueva museología (Lacouture Fornelli 1996:13).

De esta manera, el interés de este texto por abordar la exposición conmemorativa de la UNAM va más allá de una mera descripción museográfica: inquiere los significados y contenidos culturales y políticos que, a decir de Marta Dujovner (1995:27-63), es posible vislumbrar a partir de la revisión de la construcción de este discurso.

\section{9-1979. Autonomía Universitaria UNAM}

La exposición 1929-1979. Autonomía Universitaria UNAM fue inaugurada por el rector de la máxima casa de estudios del país, Guillermo Soberón Acevedo, el 22 de enero de 1979, en una ceremonia restringida a asistentes de alto nivel y con invitaciones expresas, según narró un diario citadino (El Universal 1979), y con ella se iniciaba un importante ciclo de festejos por el cincuentenario de la obtención de la autonomía universitaria. Entre los invitados más renombrados estuvieron los doctores Alfonso Noriega Cantú, Miguel León-Portilla y Ramón de la Fuente, así como el entonces miembro de la Generación de 1929, y participante del movimiento estudiantil, Baltasar Dromundo (Figura 1).

"No es una fiesta más en el calendario", fue la calificación que el rector le dio a esta importante celebración en ceremonia posterior, el 10 de julio de 1979, mientras que otros medios de comunicación la llamaron el "jubileo de oro" (Osorio Altúzar 1979; Novedades 1979a; Gaceta UNAM 1979:2-6). En ese mismo tono de reafirmación social y política de la importancia de la autonomía uni-

versitaria, el alumno Armando Carrillo Lavat pronunció en esa ocasión las siguientes palabras: "[la autonomía universitaria ayudó a] propiciar una universidad libre y autónoma de todo acontecer que no sea estrictamente universitario y académico" (Ader 1979). Tras estos discursos el acto concluyó con la participación del Coro de la UNAM, el cual interpretó las obras Gaudeamus igitur, de Joahnnes Brahms, y "Cum Sancto Spiritu", de la Misa en si menor de Johann Sebastian Bach (UNAM 1988:4-7).

El aviso que desde inicios de 1979 circuló la propia universidad con su cartelera "Los universitarios hoy" en diarios nacionales, tales como Novedades, señaló que la apertura de la Exposición sería una "inauguración de los festejos para conmemorar el cincuentenario de la Universidad Nacional" (Novedades 1979b). La invitación al público difundida en la prensa indicó que los estudiantes y maestros, así como "trabajadores con credencial de la UNAM, UAM, INBA y tarjetahabientes Conacurt y CREA", recibirían un descuento en el pago de su ingreso (Excélsior 1979). La clausura se programó para el 31 de agosto, pero el éxito — tuvo más de 140000 asistentes de enero a septiembre (UNAM 1980:75) — Ilevó a prolongarla un mes más.

Esta celebración institucional incluía: diversos actos académicos, entre los que destacan los ciclos La autonomía contemplada por los líderes del 29 y La autonomía y los maestros, el Seminario Internacional sobre Problemas de Legislación Universitaria, 20 mesas redondas sobre la Universidad Nacional y problemas nacionales, y el congreso Significado y Esencia de la Autonomía Universitaria 
en Latinoamérica; la publicación de investigaciones y textos alrededor de la historia universitaria —más de diez títulos dentro de la colección Cincuentenario de la Autonomía Universitaria-; un certamen para la mejor tesis profesional que abordara el tema de la autonomía universitaria; competencias deportivas como la "Carrera de la Autonomía", con la participación de aproximadamente 50 atletas, que inició frente a las hermosas puertas ferrosas del Palacio de Minería y concluyó en Ciudad Universitaria, así como algunos otros actos de repercusión política, como la iniciativa presidencial para garantizar la autonomía universitaria "por medio de la adición de la fracción VIII al artículo tercero de la Constitución Política" (UNAM 1980:76).

Fueron muy relevantes, por ejemplo, la entrega, el 11 de febrero, de doctorados honoris causa a Claude Levi-Strauss, Alexander Oparin, Octavio Paz, Rufino Tamayo, Alejandro Gómez Arias y Edmundo O'Gorman (UNAM 1994:176-177); las construcciones de los edificios del Centro Cultural Universitario, entre los cuales están el Teatro Juan Ruiz de Alarcón, el Foro Experimental Sor Juana Inés de la Cruz y los edificios de la Biblioteca y Hemeroteca nacionales y del Centro de Estudios sobre la Universidad (CESU), ahora Instituto de Investigaciones sobre la Universidad y la Educación (IISUE).

Las celebraciones no dejaban duda de que desde el fin de la época porfirista y la conclusión de la reyerta revolucionaria del siglo $\mathrm{xX}$, la presencia de la Universidad Nacional paulatinamente ha devenido, así, fundamental para México. La UNAM se convirtió en uno de los organismos capaces de transformar numerosas contradicciones que frenaban el desarrollo del país: esto lo demostró la exposición museográfica.

\section{La museografía}

La Exposición, coordinada por Rodolfo Ribera y un equipo de especialistas, ${ }^{2}$ se montó en las instalaciones del Palacio de Minería, ubicado en el número 5 de la calle de Tacuba, en el centro de la ciudad de México, con base en una distribución temática articulada en 24 salas, en las que, de forma general, se describieron las funciones y la organización administrativa de la universidad, además de la autonomía universitaria, el tema histórico prioritario (IISUE/ AHUNAM/COE s. f.a).

Los ejes temáticos de las salas fueron: antecedentes, autonomía, población, docencia, investigación, extensión universitaria, intercambio académico, proyección

2 Si bien hubiéramos podido entrevistar a algunos de los integrantes de las distintas comisiones que participaron en la organización de la Exposición, que aún laboran en la universidad con importantes cargos en el organigrama, con la finalidad de conocer sus experiencias al respecto, para esta investigación resultaría más interesante conocer a los participantes directos del montaje, de los cuales desgraciadamente no tenemos huella alguna. social, recursos, oficinas general, administrativa y jurídica, joyas bibliográficas, exposiciones temporales, deportes, auditorio, galería de rectores, patrimonio artístico, instalaciones, salón de ceremonias, capilla y artículos conmemorativos.

Las evidencias fotográficas, los documentos de archivo, así como el libro Memoria de la Exposición sobre la Universidad (Jeannetti Dávila et al. 1979), nos permiten conocer el recorrido y advertir que en la disposición museográfica convivieron gráficas, fotografías, diapositivas, videos, audios y objetos de diferentes entidades universitarias (Figuras 2, 3 y 4).

La división en 24 grandes apartados, conformados por objetos emblemáticos y explicaciones puntuales, abarcó los varios espacios del tiempo universitario: su origen y estructura, sus periodos álgidos, logros y desafíos, su presencia activa en los movimientos sociales y democráticos del país, las luchas por los derechos humanos, el compromiso social de sus egresados y la identificación de sus aportes a la vida nacional.

Por ejemplo, en la sala 2, "Autonomía" — propiamente, la protagonista de la muestra-, se presentaron documentos que dan cuenta de esa potestad, reconocida en 1929, de las Leyes Orgánicas de 1929, 1933 y 1945, así como de la concepción de su escudo, cuyos rasgos propuso José Vasconcelos, y lema, también de su autoría.

En la vasta exhibición se describieron la estructura universitaria, los sistemas y aportaciones en los ámbitos de la ciencia, tecnología, arquitectura e ingeniería — para esos años, la UNAM era la entidad educativa que generaba la mitad de la producción científica de las universidades mexicanas-, cómputo avanzado, humanidades y ciencias sociales, y, además, la difusión cultural y las actividades deportivas.

A lo largo del apartado "Prospectiva" de la exposición se presentó una reflexión sobre la existencia de la UNAM, sus retos y su futuro, donde sus ex rectores y profesores eméritos hablaron de su relación con la universidad y la forma en que marcó sus vidas. En una cronología interactiva, que partió de 1910 y concluyó en 1979, se dispuso de un amplio abanico de imágenes y documentos, un mapa del antiguo barrio universitario y una base de datos de las investigaciones en proceso.

Una de las finalidades sustanciales de la UNAM: "extender, con la mayor amplitud posible, los beneficios de la cultura" (Jeannetti Dávila et al. 1979:480), se ejemplificó en la sala 8, titulada "Proyección Social", con las diferentes actividades y tareas que lograron consolidar su presencia cultural entre la sociedad, principalmente a través de la Camerata de la Casa del Lago, la Orquesta Filarmónica y Radio UNAM (con su proyecto Voz viva de América Latina, surgido en los años sesenta).

La sala 18, "Patrimonio Artístico", fue la más Ilamativa porque dio a conocer varios de los tesoros artísticos que la universidad había reunido con el paso del tiempo. 


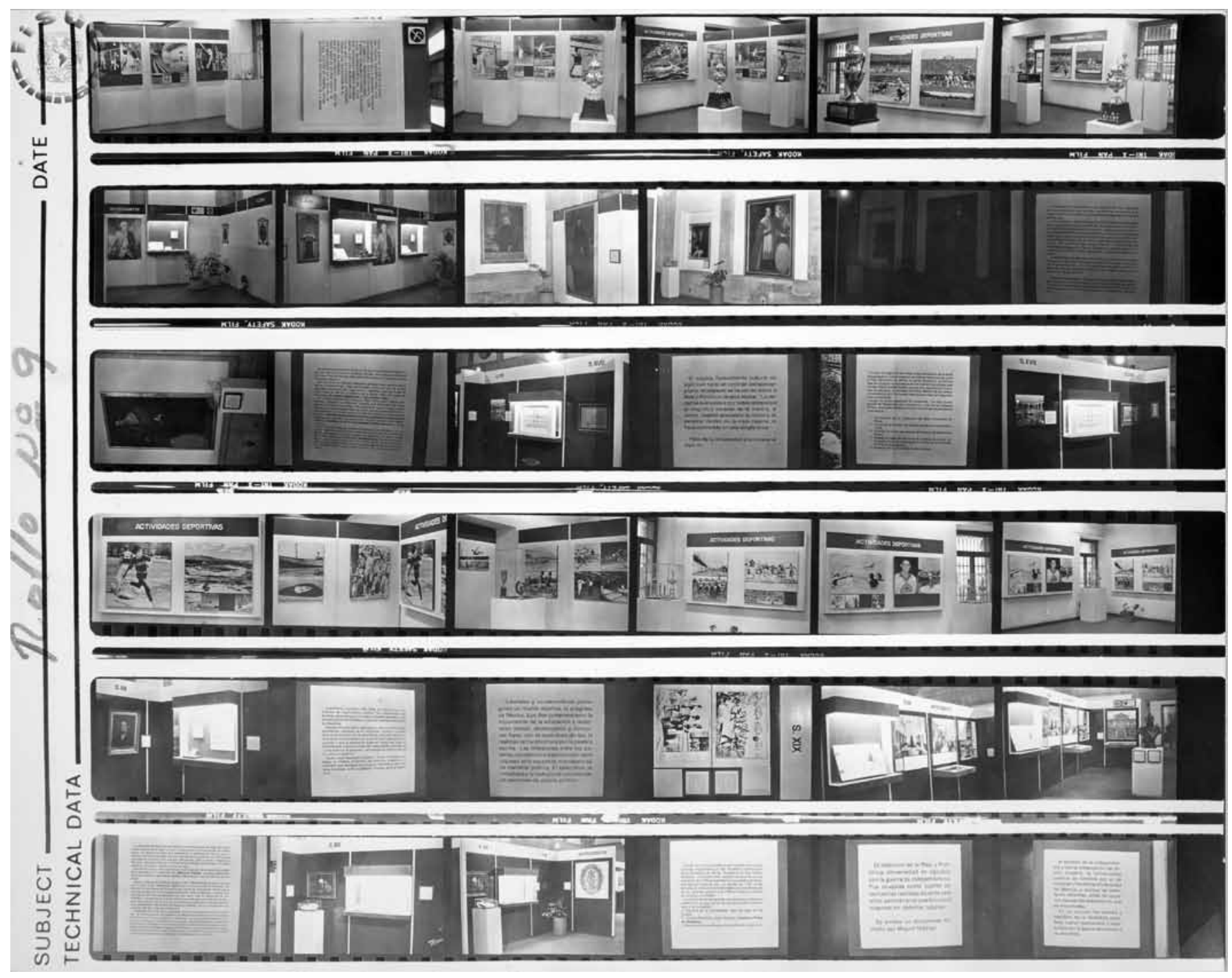

FIGURA 2. Serie de imágenes que registran parte de la exposición (Fotografía: Raimundo García Cardozo, 1979; cortesía; IISUE/AHUNAM/ Fondo Comisión Organizadora de la Exposición 1929-1979. Autonomía Universitaria UNAM, sección Investigación, caja 17, expedientes 168, 1979).

Dicha colección se nutrió, por ejemplo, con grabados, esculturas y retratos de la Academia de San Carlos, libros incunables mexicanos y diversos ejemplares cuyas primeras ediciones atesora la Biblioteca Nacional, el óleo de Juan de Miranda con el retrato de Sor Juana Inés de la Cruz que custodia Rectoría, la maqueta de Mario Pani de la Torre de Rectoría o el modelo para la Biblioteca Central de Juan O'Gorman. Todo esto ilustra la plena inmersión de la UNAM en la historia, que los visitantes experimentaron al recorrer los pasillos de la Exposición.

Distintas fotografías, montadas en las mamparas de cada sala y acompañadas de cédulas explicativas de gran tamaño, dieron relación de la actividad universitaria. Su autor fue el fotógrafo Raimundo García Cardozo (Jeannetti Dávila et al. 1979:489), quien tuvo un doble encargo: recorrer las dependencias universitarias y retratar tanto sus instalaciones como diversos aspectos de las actividades institucionales: docencia, ciencia, deporte, que realizaba la comunidad universitaria, y realizar una búsqueda iconográfica en el Archivo Histórico de la UNAM (AHUNAM), y en la Biblioteca y la Hemeroteca nacionales. Las más de 2000 imágenes resguardadas constituyen un testimonio artístico y científico de una muy extendida época de la universidad a partir de su autonomía.

Las piezas y objetos expuestos fueron reunidos mediante la aprobación de cientos de solicitudes de préstamo de la propia UNAM: el conjunto de obras de arte y distintos materiales científicos, folletos, publicaciones y otros productos tuvieron el sentido de mostrar un balance pertinente de los quehaceres de la institución (IISUE/AHUNAM/ COE s. f.b). Desafortunadamente, no se conservaron todos los listados de obra, dictámenes ni un catálogo de piezas, lo cual nos impide hacer una descripción detallada de la curaduría, pero a través de la Memoria de la Exposición (Jeannetti Dávila et al. 1979) y los documentos conservados conocemos algunos de los objetos que los visitantes apre- 
ciaron en esa ocasión. Por ejemplo, se exhibieron microscopios, telescopios y lentes, diversos aparatos de física cuántica e ingeniería, jaulas con puercos y conejos, entre otros (Jeannetti Dávila et al. 1979:426-465).

La Exposición se complementó con la presentación del "Documental general" (IISUE/AHUNAM/COE s. f.a), con duración de 20 minutos, la transmisión de 14 audiovisuales (UNAM 1980a:25) y un ciclo de cine que proyectó cortos y largometrajes realizados por egresados del Centro Universitario de Estudios Cinematográficos (CUEC) (IISUE/AHUNAM/COE s. f.c). La Comisión Organizadora de la Exposición (CEO) motivó a las dependencias y entidades a preparar conferencias y otras actividades, todo lo cual se presentó alternadamente en la sala 19, "Exposiciones Temporales".

\section{Montaje}

Años antes de 1979, conforme se acercaba la fecha del cincuenta ani-

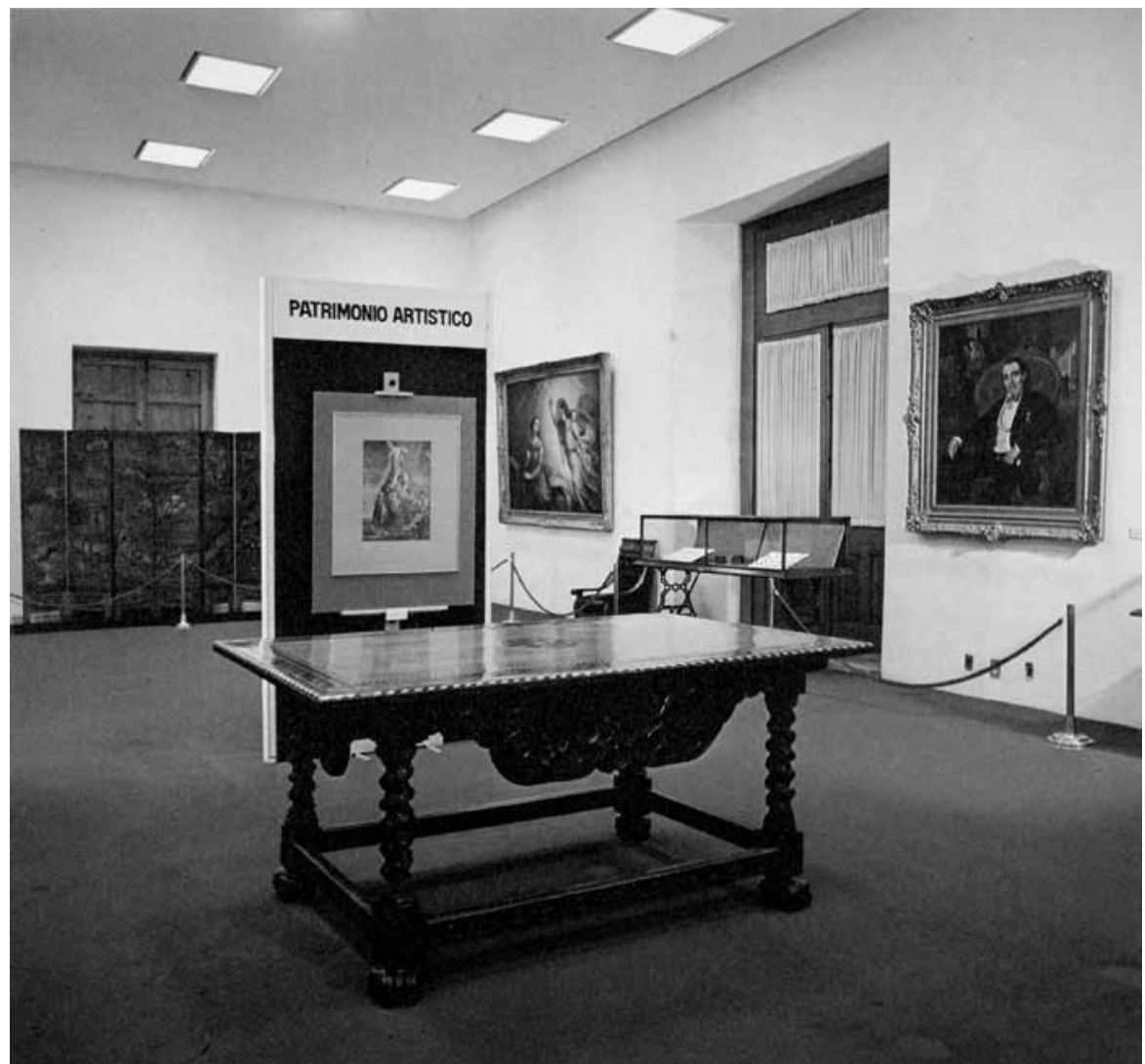

FIGURA 3. Sala de exhibición (Fotografía: Raimundo García Cardozo; fuente: Jeannetti Dávila et al. 1979:453). versario del reconocimiento de la

Autonomía Universitaria, el rector de la UNAM reunió a un equipo de trabajo al que denominó Comisión Organizadora de los festejos. Entre las varias tareas que se le asignaron estaba una prioritaria: montar una exposición museográfica que conjuntara la explicación histórica del movimiento estudiantil de 1929 y mostrara las ventajas científicas, sociales y administrativas que la autonomía había traído a la vida universitaria. Al parecer, la traza del proyecto museográfico nació a finales de 1977, y "durante meses se trabajó en redondearla y pulirla para presentarla a la consideración de las autoridades universitarias, que la aprobaron para integrar el calendario de festejos conmemorativos del cincuentenario de la autonomía universitaria" (Jeannetti Dávila et al. 1979:480). Por eso se destinaron recursos y apoyo logístico para que se llevara a cabo la Exposición. ${ }^{3}$

Desde el 14 de julio de 1978, el rector reunió a los directores de "las Facultades, Escuelas, Institutos y Centros para recordarles que en 1979 se cumplirían 50 años del reconocimiento de la Autonomía de esta Casa de Estudios, por parte del Estado" (UNAM 1979:58). De esta manera, se decidió formar tres cuerpos colegiados: "un consejo asesor integrado por los ex-rectores vivos a partir de 1929;

\footnotetext{
${ }^{3}$ En el AHUNAM/COE sólo se conservan los documentos producidos por la Secretaría Auxiliar, que se encargó del montaje, mas no relativos al presupuesto y demás asuntos contables.
}

una comisión organizadora integrada por diez maestros e investigadores eméritos de nuestra Universidad; y una comisión de apoyo integrada por los principales colaboradores del Rector" (UNAM 1979:59). En esa misma reunión se planeó que dentro del marco de las celebraciones se efectuaran más de 60 actividades.

Más tarde, la Rectoría designó en comisiones para el esperado homenaje a diversas personalidades. Así, el consejo asesor estuvo formado por los doctores Antonio Castro Leal, Ignacio García Téllez, Gustavo Baz, Mario de la Cueva, Salvador Zubirán, Ignacio Chávez y Pablo González Casanova. Encabezó la comisión de apoyo el doctor Guillermo Soberón, quien fungió como presidente, y como secretario ejecutivo, el doctor Jorge Carpizo. Los integrantes fueron el ingeniero Gerardo Ferrando Bravo y los doctores Fernando Pérez Correa, Valentín Molina Piñeiro, Agustín Ayala Castañares, Leonel Pereznieto Castro, el licenciado Diego Valadés y el arquitecto Jorge Fernández Varela.

En la COE estaban reunidos, como presidente, el rector Soberón, como secretario ejecutivo, Jorge Carpizo, y en calidad de secretarias auxiliares, la licenciada Elena Jeannetti Dávila y la contadora pública Ma. Teresa S. R. de Bracho. Los demás integrantes eran los distinguidos profesores ingeniero Antonio Dovalí Jaime, los doctores Raoul Fournier, Antonio Martínez Báez, Manuel Martínez 


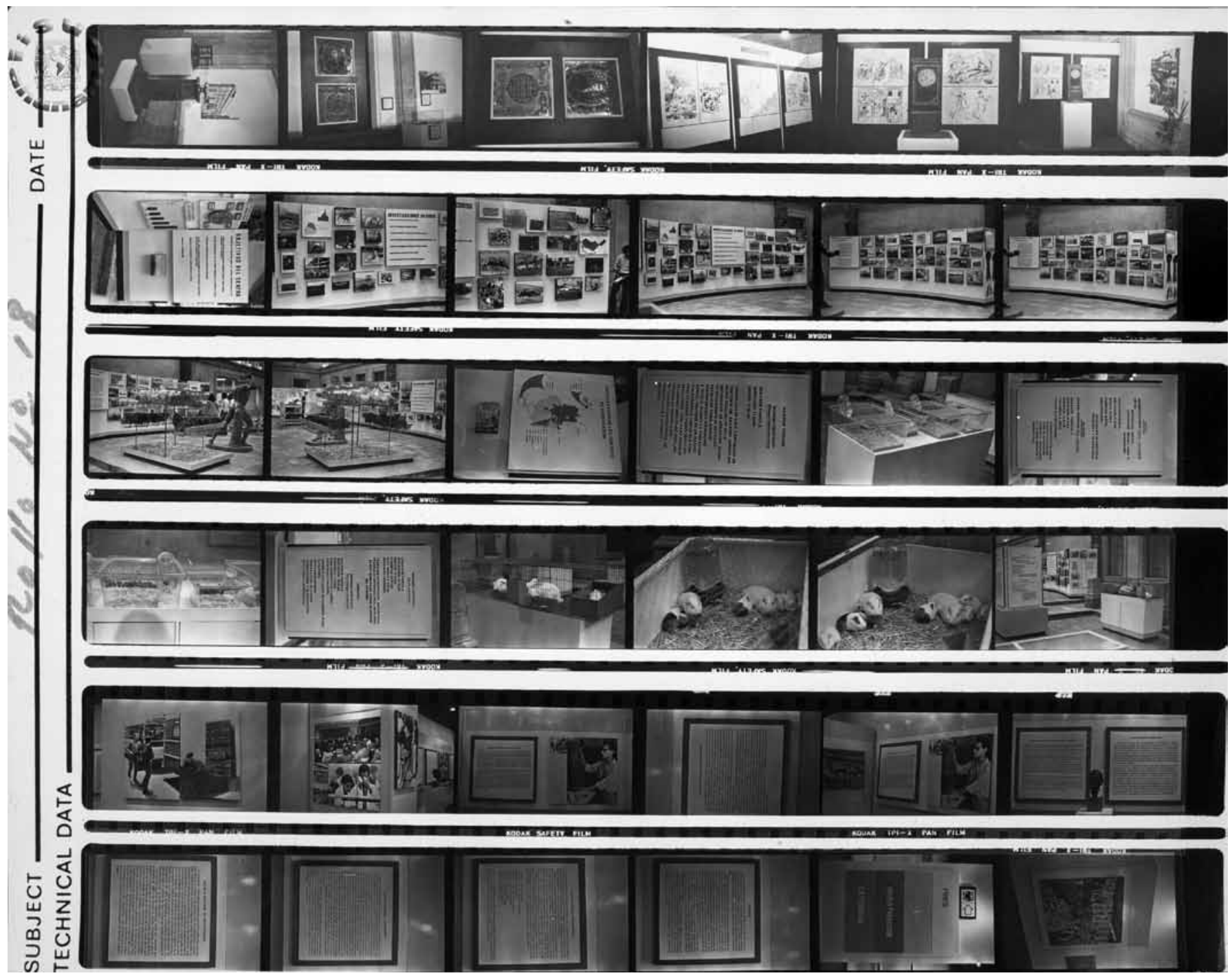

FIGURA 4. Serie de imágenes que registran parte de la exposición (Fotografía: Raimundo García Cardozo, 1979; cortesía: IISUE/AHUNAM/ Fondo Comisión Organizadora de la Exposición 1929-1979. Autonomía Universitaria UNAM, sección Investigación, caja 17, expediente 177, 1979).

Báez, Lucio Mendieta y Núñez, Eduardo Nicol, Fernando Orozco, Efrén C. del Pozo, Alberto Trueba Urbina y Leopoldo Zea.

La secretaria auxiliar de la COE, Elena Jeannetti Dávila, también dirigía el recién creado CESU, cuya participación decidida en la Exposición era acorde con una de sus finalidades: "realizar estudios acerca de la propia institución, que comprendieran aspectos históricos, legislativos, académicos, administrativos, laborales y en general todos los que constituyen la experiencia universitaria" (Pérez Cruz y Lira Soria 2000:82) y, además, tenía a su cargo elaborar "algunas cronologías y estudios de prospectiva universitaria" (Centro de Estudios sobre la Universidad 2005:7).

Entre las funciones que tenía asignada la Secretaría Auxiliar estaban: organizar reuniones con los representantes de cada entidad académica, de investigación y administrativa; reunir información pertinente tanto para una publicación conmemorativa como para la museogra- fía de la Exposición; montar las piezas, y, cuando todo finalizara, retirarlas. Colaboraron en ello los licenciados Rodolfo Ribera y José Ángel Treviño Rodríguez, quienes se desempeñaron como responsables del montaje museográfico y de la Exposición, respectivamente, mientras que Margarita Clasing fue la coordinadora técnica. Por lo tanto, la Secretaría Auxiliar fungió como una comisión de logística que, en la práctica, posibilitó la exposición museográfica (Figura 5).

La manera en que se conformó la comisión hizo posible que en las distintas reuniones se repartiera el trabajo. A Jeannetti Dávila le correspondió contactar a todos los directores de dependencias y entidades universitarias, y, a partir del nombramiento de un representante de cada una —que simplificó la labor-, solicitarles apoyo para la Exposición.

El enlace establecido permitió recabar toda la información pertinente bajo un esquema predeterminado. En 


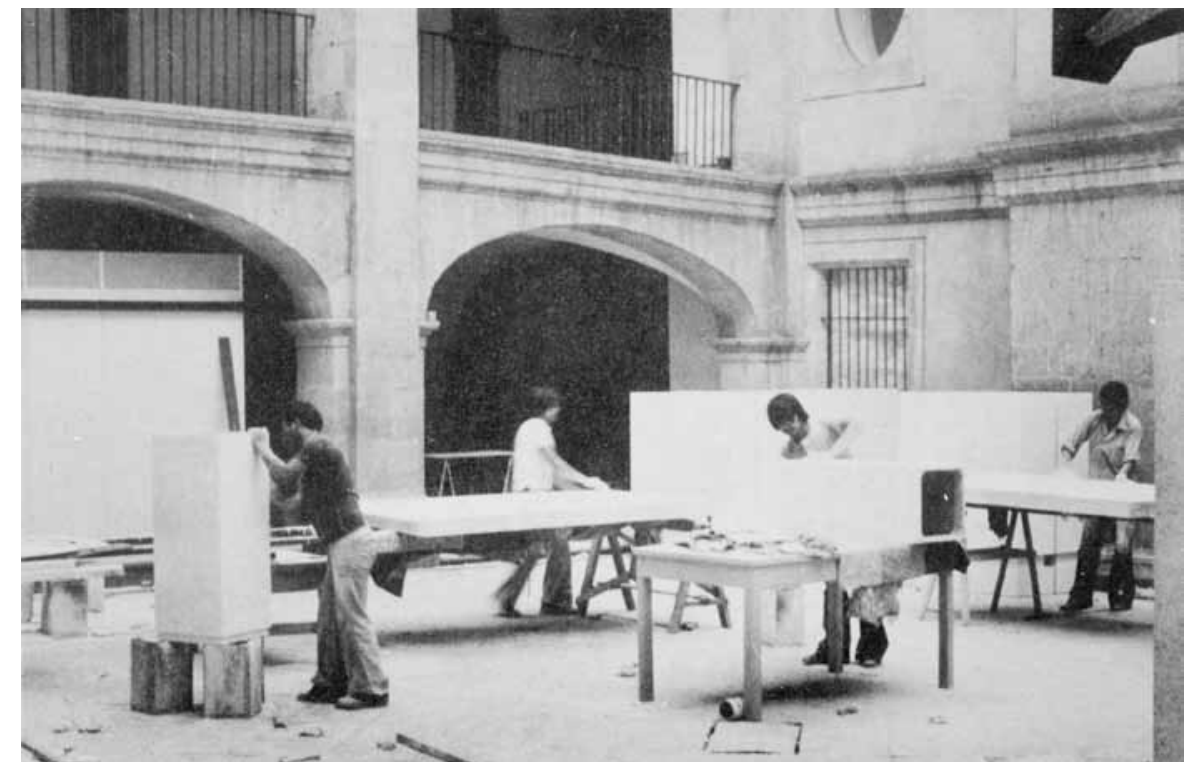

FIGURA 5. Preparación de mamparas y mobiliario museográfico (Fotografía: Raimundo García Cardozo; fuente: Jeannetti Dávila et al. 1979:478).

agosto de 1978, la comisión envió el cuestionario que inquiría acerca de sus objetivos, funciones, actividades e historia:

1. Dé una breve reseña histórica de su dependencia. 2. Defina por separado cuáles son los fines específicos de la dependencia en materia de: a) docencia, $b$ ) investigación, c) difusión de la cultura, d) apoyo a alguna de las anteriores, y forma en que se realiza. 3. Para cada uno de los apartados anteriores señale las contribuciones más sobresalientes de la dependencia desde 1929, o a partir de su creación, hasta la fecha. 4. Defina la proyección social de su dependencia: a) en relación con la comunidad universitaria, $b$ ) en relación con la sociedad en general; su impacto económico, político, cultural (IISUE/AHUNAM/ COE s. f.d).

Los representantes entablaron un trato muy estrecho con la comisión, de forma tal que se animaron a proponer materiales y objetos para la Exposición; buscaron documentos y publicaciones en sus archivos, los cuales ayudaron a repensar su dependencia como una unidad dentro de una institución con una historia propia y, al mismo tiempo, fragmento de una mayor (IISUE/AHUNAM/COE s. f.e). Así, contribuyeron con artículos, pequeñas publicaciones y trabajos de exposiciones anteriores, los cuales sirvieron para plantear antecedentes, funciones, objetivos y actividades. Tal fue el caso de la Escuela Nacional Preparatoria, que en 1967 había celebrado su centenario con, entre muchas actividades más, una exposición, cuyo guión museográfico retomó para el nuevo festejo (IISUE/ AHUNAM/COE s. f.f). La Facultad de Medicina, por su parte, presentó útiles investigaciones históricas sobre el Palacio de Medicina y el desarrollo de la disciplina (IISUE/ AHUNAM/COE s. f.g). La Dirección General de Publicaciones retrocedió en el tiempo hasta la sociedad Impresora y Editorial Mexicana y su acta constitutiva, de 1935 (IISUE/AHUNAM/COE s. f.h). Resalta la historia del Instituto de Astronomía, la cual planteó el desarrollo del Observatorio Astronómico Nacional como su antecedente (IISUE/AHUNAM/COE s. f.i).

Otros organismos, en cambio, se disculparon con la Comisión Organizadora de la Exposición, debido a que por su reciente creación no contaban con registros. Éstos fueron los casos de las direcciones generales de Asuntos del Personal Académico y de Obras, la Coordinación de Extensión Universitaria y la Comisión de Estudios de Costos Académicos (IISUE/AHUNAM/COE s. f.j).

En los nueve meses que la Exposición duró abierta al público, se dieron cita innumerables incidencias. Por ejemplo, hubo robo de algunas medallas conmemorativas expuestas en las vitrinas; algunas piezas se laceraron y rompieron durante su traslado o embalaje (IISUE/AHUNAM/COE s. f.k), y otras más fueron devueltas sin siquiera haberse expuesto, tal vez por falta de espacio.

Al finalizar la Exposición, el retorno de las piezas se convirtió en la actividad prioritaria, la que concluyó $-\mathrm{y}$, con ésta, los trabajos de la comisión- en el año 1980.

\section{Los efectos de la Exposición en el contexto de la museografía universitaria}

Resulta necesario hacer un breve recorrido del quehacer museístico que la UNAM ha desarrollado, por el que hoy, además de ser un centro de referencia obligado a escala nacional e internacional, es anfitrión de artistas de gran talla. Este apartado nos ayuda a contextualizar la Exposición y conocer su impacto.

A partir de 1929, tras el logro de la autonomía universitaria, el patrimonio mobiliario e inmobiliario de la universidad se consolidó, con lo cual se confirmó su papel de custodio de los acervos de investigación y docencia, y dejó el patrimonio histórico y artístico procedente de la Academia de San Carlos a resguardo de la Secretaría de Educación Pública, así como de los museos de los institutos nacionales de Antropología e Historia y de Bellas Artes y Literatura.

La mayoría de los objetos de arte y científicos que dieron origen a las colecciones museísticas de la Universidad Nacional originalmente dedicadas a la enseñanza proviene, entonces, de los acervos científicos y naturales de las escuelas nacionales Preparatoria, de Ingenieros, de Medicina y de Geología, pero fundamentalmente del haber artístico de la Academia de San Carlos, de la que 
conservó una parte de las piezas de yeso que Manuel Tolsá trajo de España, algunos de los grabados y objetos de numismática, medallas y troqueles (Rico Mansard 2003:70-75).

No fue sino hasta los años sesenta y setenta del siglo $\mathrm{xx}$, en el contexto de la concentración de la mayoría de las actividades de la UNAM en la actual Ciudad Universitaria, cuando se desarrollaron proyectos en materia museística muy significativos para ella. Por ejemplo, se abrieron varias sedes para exposiciones temporales y se inauguró el Museo Universitario de Ciencias y Artes (MUCA). También se abrieron museos académicos dependientes de institutos y facultades. Entre las exposiciones universitarias más llamativas, y concurridas, están las nombradas Arte precolombino del Golfo y el primer Salón de Pintura Estudiantil de la UNAM, inauguradas en febrero de 1960.

Este periodo fue, tal como lo señala Rico Mansard (2003:75-76), de transición: los museos giraron hacia un mundo más abierto, especializado y demandante; se planearon grandes áreas de exhibición; se montaron museografías atractivas; se organizaron servicios educativos para distintas audiencias, y, principalmente, se hizo eco a la promoción del Consejo Nacional de Difusión Cultural y a la categoría de museo universitario, en revisión en el ámbito internacional años antes, "ampliando sus funciones $[. .$.$] para convertirse en espacio cultural alternativo,$ dinámico e incluyente" (Rico Mansard 2003:76; 79).

En términos institucionales, la intensa labor museográfica desplegada en esas décadas por el MUCA y el Museo Universitario del Chopo (desde 1975), además de la experiencia de la Exposición de la Autonomía Universitaria (1979), consolidó el Departamento de Museos y Galerías, que en 1980 se reestructuró como Centro de Investigación y Servicios Museológicos. La maestra Helen Escobedo, quien fue directora del Departamento de Galerías y Museos desde 1961 hasta 1978, impulsó la entrada del arte vanguardista a la universidad —una de las mayores aportaciones de los museos universitarios-, lo que permitió que coincidieran exposiciones de carácter clásico o revisiones académicas con exhibiciones polémicas (Escobedo 2008).

Este proyecto de ampliación del público asistente a los museos universitarios hacia otros sectores de la sociedad aparte de los propios fue visible en el tipo de montaje que se hizo a finales de la década de 1970 en la UNAM. Ejemplo de esto fueron las exposiciones De recientes órbitas celestes, una mirada al universo y Ochenta años del cine en México, ambas presentadas en el Museo Universitario del Chopo, además de la que comentamos, sobre la Autonomía Universitaria.

Respecto de esta última, su impacto fue inaudito, ya que en los siguientes meses se inauguraron 54 exposiciones temporales en diferentes espacios, con lo cual se brindó una experiencia útil para actualizar las premisas museológicas universitarias. En esa misma línea está el Museo de la Autonomía Universitaria, localizado en el Palacio de la Autonomía, Licenciado Verdad, núm. 2, Centro Histórico de la ciudad de México. Inaugurado en 2004 con base en una museología semejante a la de la Exposición de 1979, cuenta con 24 monitores donde se presentan imágenes de las actividades prioritarias de la UNAM, así como de su patrimonio, y se proyectan audiovisuales que rememoran los acontecimientos relacionados con el movimiento de 1929 (Tejeda 2010).

Las exposiciones universitarias conmemorativas han sido un ejercicio de revitalización de los significados institucionales sobre su propio desarrollo. Ello bien lo demostró la de 1979, pero también ha sido visible en otras posteriores, como las referentes al centenario de la universidad montadas en 2010: Tiempo Universitario. 100 años de la Universidad Nacional en el Museo del Antiguo Colegio de San Ildefonso, Constructores: Ios universitarios en el desarrollo del México moderno (1910-2010) en el Palacio de Minería y Cien años de pintura en la Universidad Nacional en el Museo Universitario del Chopo (García Barragán 2011:375).

\section{Conclusiones}

Desde una perspectiva histórica, la mayor contribución de la Exposición 1929-1979. Autonomía Universitaria UNAM es que se trató de una exhibición frontera, o parteaguas, entre el viejo y el nuevo quehacer museográfico universitario. La pertinencia de estudiarla aumenta debido a que su carácter temporal la destinaría a la destrucción de sus huellas materiales, pero no sucedió así: aún ahora es posible conocer esa experiencia a partir de las evidencias históricas conservadas en el AHUNAM.

Desde el punto de vista de la museología, puede hacerse una rápida evaluación de otras ventajas de la Exposición de 1979, al centrarnos en las Ilamadas doce acciones museográficas (Lacouture Fornelli 1996:12). Esas seis parejas quedarían en la Exposición de la siguiente forma: respecto de la primera, Investigación-Recolección, la propia Comisión Organizadora de la Exposición se dedicó durante meses a reunir datos e imágenes para construir una propuesta museológica acorde con las intenciones institucionales del festejo, trabajo que se fincó en la cooperación de todas las dependencias universitarias. Sobre la pareja 2, Catalogación-Documentación, la comisión llevó un puntual registro de los objetos y documentos seleccionados, además de que elaboró la Memoria de la Exposición, instrumento que funge como un catálogo de piezas. En relación con la Conservación-Restauración (pareja 3), en los casos necesarios la comisión aplicó, tras haber efectuado un breve diagnóstico, distintas medidas de restauración. Acerca del discurso de la cuarta, Exposición-Explicación, mediante las fotografías presentadas podemos observar que fue plano y tedioso, pero, al combinarlas con elementos novedosos (como la exhibición de jaulas con conejos y otros animales, materiales no 
considerados museográficos, y la presentación de audiovisuales y otras actividades culturales), lo señalan como un discurso efectivo, articulado en objetos y cédulas. En lo tocante a la pareja 5, Educación-Difusión, la Exposición logró su objetivo pedagógico, ${ }^{4}$ al haber transmitido cómo la autonomía universitaria contribuyó con la sociedad, mensaje que llegó a más de 140000 visitantes debido a una amplia, aunque sencilla, difusión, ${ }^{5}$ esto último totalmente relacionado con la pareja 6, EvaluaciónComunicación.

Los museos y exposiciones implantan un sentido en la sociedad a partir de sus tareas prioritarias: "recolectar, conservar, investigar, interpretar, exhibir y comunicar diversas clases de evidencias primarias" (Morales Moreno 1996:60), además de que "crea[n] otro contexto de interpretación de las cosas" (Morales Moreno 1996:72). Ello sucedió con la Exposición de 1979, ya que generó, con argumentos sólidos y científicos, un estado de jubileo y éxtasis por la autonomía universitaria.

A pesar de que la Exposición no fue atractiva ni llamativa desde el punto de vista museístico, cumplió con las expectativas de las autoridades universitarias y significó una favorable experiencia para las siguientes muestras de la UNAM.

\section{Agradecimientos}

Las autoras agradecen el apoyo de Fernando Lizárraga y Fernando Hernández, así como los comentarios de Lorena Botello, para la conformación de este reporte.

El Comité editorial de la revista Intervención extiende su gratitud al IISUE/AHUNAM/ Fondo Comisión Organizadora de la Exposición 1929-1979. Autonomía Universitaria UNAM por el material gráfico incluido en este REPORTE.

\section{Referencias}

Ader, María Isabel

1979 "10 de julio de 1929 a 1979, Cincuenta Años de Autonomía Universitaria. Emotiva conmemoración", Revista de la Educación Superior, México, ANUIES, 8 (31), documento electrónico disponible en [http://publicaciones.anuies.mx/revista/31].

CESU/UNAM (Centro de Estudios sobre la Universidad) c 2005 Centro de Estudios sobre la Universidad y la Educación [“Treinta aniversario, 1976-2006”], México, UNAM.

Dujovner, Marta

1995 Entre musas y musarañas. Una visita al museo, Buenos Aires, FCE.

\footnotetext{
${ }^{4}$ En el AHUNAM/COE no se cuentan con materiales pedagógicos de apoyo, como folletos y cuadernillos, que informen de la Exposición.

${ }^{5}$ No hay en el AHUNAM/COE indicios de estudios de público (encuestas, cuestionarios o entrevistas) que nos indiquen el porcentaje de asistentes externos a la comunidad universitaria, por lo que su ausencia nos impide valorar el impacto real de la Exposición en la sociedad mexicana.
}

El Universal

1979 "Cincuentenario de la Autonomía", El Universal, 23 de enero: 20.

Escobedo, Helen

2008 "Nuevas rutas para los museos universitarios", ponencia presentada en el Sexto Congreso Internacional de Museos Universitarios, México, UNAM.

Excélsior

1979 "Los universitarios hoy", Excélsior, 14 de mayo:8E.

Gaceta UNAM

1979 "Encuentro de Representantes de las Instituciones de Educación Superior que participan en el Programa de Colaboración Interuniversitaria, Galindo, Querétaro.", Gaceta UNAM. Órgano informativo de la Universidad Nacional Autónoma de México, III (7): 1-16.

García Barragán Martínez, María Elisa 2011 "Modelos educativos de la Academia de San Carlos", en VV. AA., Tiempo universitario. 100 años de la Universidad Nacional, México, UNAM, 25-41.

IISUE/AHUNAM/COE Fondo Comisión Organizadora de la Exposición 1929-1979. Autonomía Universitaria UNAM

1979, sección Investigación, caja 17, expedientes 168 y 177. s. f.a "Exposición 1929-1979. Autonomía Universitaria UNAM", Folleto-tríptico, Caja 1, Exp. 1.

s. f.b "Peticiones, listados, recibos, inventarios y resguardos de obras de arte y bienes artísticos", Serie, Cajas 11-12, Exps. 97-103.

s. f.c Caja 7, Exp. 62.

s. f.d Caja 1, Exp. 1.

s. f.e "Recopilación informativa de las dependencias y entidades universitarias de Docencia"; "recopilación informativa de las dependencias y entidades universitarias de Investigación Humanística"; "recopilación informativa de las dependencias y entidades universitarias de Investigación Científica"; "recopilación informativa de las dependencias y entidades universitarias de Proyección Social"; "recopilación informativa de las dependencias y entidades universitarias de Recursos"; "recopilación informativa de las dependencias y entidades universitarias de Administración", y "recopilación informativa de las dependencias y entidades universitarias de Estructura de Gobierno y Jurídico", Series, Cajas 1, 3-10, Exps. 4-94.

s. f.f "Exposición Centenario ENP (mayo 14-junio 21 de 1968)", Caja 3, Exp. 16.

s. f.g Caja 4, Exp. 26.

s. f.h Caja 9, Exp. 76

s. f.i Caja 7, Exp. 52.

s. f.j Cajas 8-9, Exps. 51, 69, 78 y 82.

s. f.k Caja 12, Exp. 152.

Jeannetti Dávila, Elena, Rodolfo Ribera, Aurelio de los Reyes, Omar Arroyo y Magdalena Clasing (coords.)

1979 Memoria de la Exposición sobre la universidad (Cincuentenario de la Autonomía de la Universidad Nacional de México XI), México, UNAM.

Lacouture Fornelli, Felipe

1996 “La museología y la práctica del museo. Áreas de 
estudio", Cuicuilco. Revista de la Escuela Nacional de Antropología e Historia, 3 (7): 11-30.

Monroy Casillas, Ilihutsy

2010 "Guía particular, inventario y catálogo por expediente del Fondo Comisión Organizadora de la Exposición 19291979. Autonomía Universitaria UNAM", documento mecanoescrito, México, IISUE/AHUNAM.

Morales Moreno, Luis Gerardo

1996 “QQué es un museo?”, Cuicuilco. Revista de la Escuela Nacional de Antropología e Historia, 3 (7): 59-104.

Novedades

1979a "Jubileo de oro del alma mater. Ceremonia inaugural de los actos para conmemorar la autonomía universitaria", Novedades, 23 de enero: 9.

1979b "Los universitarios hoy", Novedades, 21 de enero: 10.

Osorio Altúzar, Federico

1979 "La autonomía universitaria. Jubileo de oro", Novedades, 22 de enero: 5.

Pérez Cruz, José Enrique y Enrique Lira Soria 2000 "Archivo Histórico de la UNAM: tres décadas de vida", en Gustavo Villanueva Bazán (coord.), Teoría y práctica archivística I, México, CESU/UNAM: 77-85.

\section{Resumen}

Este reporte analiza la exposición conmemorativa 19291979. Autonomía Universitaria UNAM como una exhibición frontera entre un viejo y un nuevo hacer de la museología universitaria mexicana, a partir de la descripción de su contexto, su concepto museográfico y su montaje. Con ello se busca comprender, con base en diversos tipos de testimonios (notas de prensa y documentos resguardados en el Archivo Histórico de la UNAM), las formas de hacer museos en el ámbito universitario, con la finalidad de evidenciar la importancia que las exhibiciones del segundo y tercer tercio del siglo XX tuvieron tanto en la sociedad mexicana como en la conformación de la identidad de la UNAM.

\section{Palabras clave}

Museografía; recintos universitarios; historia de exposiciones; UNAM
Pérez San Vicente, Guadalupe

1979 "La extensión universitaria. Notas para su historia", en Jorge Fernández Varela (coord.), La extensión universitaria, t. I (Cincuentenario de la Autonomía de la Universidad Nacional de México VI), México, UNAM.

Rico Mansard, Luisa Fernanda 2003 "Entre gabinetes y museos. Remembranza del espacio universitario", Perfiles Educativos, xxv (101): 66-96.

Tejeda, Ana Rita

2010 "Un palacio más que centenario. 100 años de cultura universitaria", documento electrónico disponible en [http:// www.cultura.unam.mx/?tp=articulo\&id=1187\&ac=mostrar \& Itemid=268\&ct=316], consultado en abril de 2013.

UNAM

1979 Informe del rector 1978, México, UNAM.

1980 Informe del rector 1973-1980, México, UNAM.

1980a Informe UNAM 1979, México, UNAM, t. 1.

1988 La universidad en el umbral del siglo XXI, México, UNAM. 1994 La universidad en el espejo, México, UNAM.

\section{Abstract}

This text examines the commemorative university exhibition 1929-1979. Autonomía Universitaria, UNAM as an example of an exhibition that borders between an old and a new way of doing university museology in Mexico, starting with a detailed description of the context, museography and mounting of the exhibits. It attempts to understand through different testimonies in press releases and documents preserved in the Historical Archive of the UNAM, the ways of doing museography in university spaces to demonstrate the importance that exhibitions in that period had on Mexican society and on shaping the identity of the UNAM.

\section{Key words}

Museography; university spaces; history of displays; UNAM

Título en inglés: Museography over Time. Analysis of a Commemorative University Exhibition in 1979 